\title{
Editorial: Decolonising Rural Ecologies of Teaching and Learning
}

\author{
Bekithemba Dube
}

ORCID iD: https://orcid.org/0000-0003-4327-7838

\section{Dipane Hlalele}

ORCID iD: https://orcid.org/0000-0003-4455-4876

\section{Macalane Malindi \\ ORCID iD: https://orcid.org/0000-0002-6378-0265}

Emergent rural epistemologies from the South, find themselves in contested terrain in the academic space. In competition with colonially inspired epistemologies from the North as well as reigning epistemologies serving urban areas and city life, they are challenged to set their own knowledge production agendas creatively and engage with them constructively. Aiming at serving and empowering rural communities, they should problematize the South-North and rural-urban epistemological divides creatively, and produce the requisite rural knowledge epistemologies that serve the objectives of rural sustainable development. They need to negotiate and articulate rural epistemological repositories, social networks, treasured values, moral wisdom and social cohesion, imaginatively and resourcefully in the broader universe of knowledge production relevance, equality and epistemic transformation and development.

These resources, so typical of rural communities, should be intellectualised, harnessed and mobilised in constructive and enabling epistemological networks that serve rural, communal and upwardly mobile wealth creation, modernisation, and socio-economic advancement. As such, rural, home-grown epistemological production would not only reclaim its own space for knowledge production in the broader, universally contested epistemological arena, but also contribute its own intellectualised sociocultural wealth and wisdom 
constructively, to the globalising and digitalising world.

Furthermore, cognisant of the challenge of fostering a constructive and productive epistemic framework for rural learners that attend higher education institutions in the South, decolonial pedagogies should foster positive and affirmative worldviews, human dignity, and knowledge and skills development for rural self-advancement. This should be done in the context of the history of the decolonial experience of the resistance to slavery, and the confrontation of, and struggles against imperialism and colonization, and the achievements of independence and self-rule, as the dominant trajectory in the story of the modern world (Ndlovu-Gatsheni 2013:11-12).

A centrally significant constituent focus in this narrative, is the struggle against the dehumanisation, binarism and hierarchisation of colonising knowledges and the triumphs of the assertion of human dignity, freedom, equality and sustainable development against the imbalances of power, knowledge and the colonial legacy (Sithole 2014). It challenges rural pedagogies to be positively and practically, not only rethinking the very constitution of the present, but also the construction and reconstruction of African subjectivity as an important and integral project in rurally focused teaching and learning.

In the face of the ever-growing divide between the rural and urban, and the South and the North, the innovative engagement of this educational challenge is needed today, more than ever before. It is along the two trajectories - knowledge production and pedagogy innovation - that the Qwaqwa Campus of the University of the Free State, situated in the rural Afromontane region of the Maloti, invited scholars nationally and internationally to contribute theoretical and empirical papers on how rural epistemologies can be a force to be reckoned with in the epistemic space of sustainable development for all.

This issue of Alternation is the result of more than eighty papers that were delivered at the very productive and far-reaching conference. We want to thank all the participants from all parts of South Africa, and we hope that the effects and dynamics of the conference as wel las this issue will provide a foundation for further thinking and developments.

For easy reference, below, we present the abstracts of the articles in this issue, from the authors in this issue, as to their respective research contributions, and scholarly focuses and related arguments. Thank you for your diligence and hard work in bringing this work to fruition. 
In 'Re-Thinking the Value of Land-based Livelihoods in Former Bantustans of Post-Apartheid South Africa', Takunda Chirau, Precious Tirivanhu and Owence Chabaya explore the value of land-based livelihoods in former bantustans of post-apartheid South Africa. South Africa, particularly the former bantustans, continue to endure massive inequalities with respect to economic opportunities and poverty remains highly prevalent in the former bantustans. However, agriculture-based livelihoods (crop and livestock production) contribute to sustenance of female headed households. This study applied indepth interviews and questionnaires to a sample of female headed households, using a purposive non-random sampling procedure using Cala, in Eastern Cape province of South Africa as a case study. Findings indicate that, besides farming economy dwindling in the rural areas, land-based livelihoods continue to provide a safety net for households for both consumption and income generation. This contribution cannot be underestimated as households continue to hang on in face of ever-increasing poverty. The study concluded that it is important for the government and civil society to build on the current farm livelihoods and augment their economic value.

In Lesotho HIV and AIDS is a national crisis with many rural citizens being either affected by or infected with HIV and AIDS. So severe is the rate of infections that HIV prevalence since 2013 has increased from 23 percent to 25 percent, making Lesotho the country with the second highest HIV and AIDS infections worldwide. Of these infections, a substantial percentage is young people. However, learners are also variously affected by the pandemic. Education is generally regarded as a significant factor in the fight against HIV and AIDS. Thus, Lesotho developed the Lesotho Education Sector HIV and AIDS Policy in 2012, which articulates the education sector's response to the HIV and AIDS crisis. It is against this backdrop that the article by Kelello Rakollobe and Kevin Teise, 'Realities Regarding the (Non)Enactment of the Education Sector HIV and AIDS Policy in Rural Lesotho', reports on a study conducted to explore the realities regarding the (non) enactment of the LESHAP (2012) in particular, schools in the rural areas of Lesotho. Data were generated through semi-structured interviews with various stakeholders in Lesotho education. Findings from the study suggest that the aims and objectives of the LESHAP (2012) might not be realised because of various factors which negatively impact its effective enactment. These factors include a lack of knowledge and training; a lack of school specific policies; culture; a lack of training; the absence of the policy at school; a lack of school specific 
HIV and AIDS policies; religious convictions; and the attitudes of teachers about condoms. The article concludes with recommendations aimed at enhancing the enactment of the LESHAP 2012.

'Investigating Patterns of Mathematics Talk in a Rural South African Classroom of an Early Career Primary School Teacher' is the result of an interpretivist research design, by Benjamin Shongwe, that reports on an investigation whose purpose is to explore the case of the patterns of talk through which an early career mathematics teacher and her learners interact to construct mathematical knowledge in a South African rural school. Despite increased interest in classroom interactions in primary mathematics across all grades, the problem is that little research has focused on measuring the level of communication patterns taking place in mathematics classes of early career teachers. Exploring the level of communication patterns in mathematics classrooms entails exploration of conjecturing given that conjecturing is fundamental to learning mathematics. To characterise classroom communication patterns, classroom interactions in three lessons $(n=48)$ of a conveniently selected early career teacher were observed. In framing this study, I draw on various aspects of Vygotsky's sociocultural theory (SCT). To corroborate data obtained from these observations and the RTOP was adopted to detect the degree to which the early career teacher's classroom instruction was reformed. The findings indicate that approximately two thirds of the communication patterns were authoritative and therefore low in the level of interanimation of learners' conjectures. Recommendation for future research is for studies that incorporate both rural and urban schools so that broader understandings of findings can be gained to better understand the problem prior to designing intervention programmes. The implication of these findings for teacher education programmes is that there is a need to foster instructional practices that encourage the delivery of mathematics that is honest to mathematics as a discipline and honours mathematics learners. From a gender equity position, and in light of a plethora of intervention efforts particularly targeting female learners, future research could shed light into how participation and the quality of classroom talk are distributed across gender.

Although higher education as a sector is open for access to many more students than has been the case in the past, students from rural backgrounds continue to be confronted with many barriers which construct them as misfits for university studies. In "“Being in" and "Being of": Reflections on Being a Rural Working Class Student, and Academic Support Practitioner, in Higher 
Education', Samukelisiwe Khumalo present reflections on how being a student from a rural community has influenced her practice as an educator who has coordinated Academic Monitoring and Support at a South African university. It examines layers of academic and non-academic challenges experienced by students from rural working class backgrounds, through the lens of her own narrative. Using Participatory Narrative Inquiry (PNI), she includes her personal experiences and insights as a participant researcher and interrogates these experiences and observations using Bourdieu's (1985) cultural capital theory. The evidence suggests that the growth in the number of students from rural socioeconomic backgrounds entering higher education is not matched by the preparedness of students for tertiary study, or by institutional readiness to support and nurture these students. She highlights lessons learnt for rural schools' praxis.

The article by Dipane Hlalele and Moeketsi Mosia, 'Teachers' Sense of Community in Rural Learning Ecologies', reports on the findings of a baseline study that sought to explore teachers' sense of community in so far as it contributes to sustainable rural learning ecologies. Community is a group of people who, together, share the feeling they belong to something, can influence and be influenced by one another, and can have their needs fulfilled by fulfilling the needs of the group. This small-scale mixed-method (quantitative and qualitative) study administered the revised 24-item Sense of Community Index (SCI-2) questionnaire on 161 male and female teachers randomly selected from rural schools in the eastern Free State region of South Africa. The questionnaire was tested for reliability using the Cronbach alpha coefficient and was found to have a reliability score of 0.71 , indicating an acceptable reliability coefficient. In addition, three narratives from teachers in one rural school were sourced. Findings indicated that teachers who stay in urban areas but are employed in rural schools evinced a similar sense of belonging, membership, shared emotional connection as well as influence as their counterparts who stay in rural learning ecologies.

The article 'Decolonising the Teaching of Mathematics in Rural Learning Ecologies by Using Indigenous Games' by Tshele Moloi aims at decolonising the teaching and learning of mathematics, such that mathematics is accessible to all learners in rural ecologies. The paper uses diketo (coordination game), as an example of indigenous games to teach patterns such as linear functions in mathematics. The paper is guided by the theory of community cultural wealth. The theory views community members as experts in rural 
learning ecologies. The marginalised knowledge they possess empowers them to find their own solutions to local issues. The knowledge that learners possess from the rural learning ecologies is not used in the teaching and learning of mathematics. The researcher maintains that there are no deficiencies in the marginalised knowledge of the excluded people. As a result, the researcher tapped into the marginalised knowledge of subaltern communities to teach linear functions, using participatory action research (PAR) in generating data; hence, the involvement of community members (parents, traditional leaders), education experts (teachers, mathematics subject advisors, lecturers from institution of higher learning) and learners themselves. All the discussions by participants were captured by using tape-recorder and video camera. The generated data were analysed using Van Dijk's critical discourse analysis (CDA). CDA enabled the study to acquire deeper meanings of the text. Again, CDA assists in identifying instances of 'discursive injustices' in text and talk, and signifies a form of resistance to unethical and unjust social power relations.

In 'Decolonising Practical Space in Rural Teacher Education: The Vehicle of Peer Assessment', Cias T. Tsotetsi, Bunmi I. Omodan and Bekithemba Dube, aver that previous studies have demonstrated positives and challenges related to assessment, including peer assessment. On a positive note, various authors perceive peer assessment as being more reliable, compared to self-assessment. While peer assessment has positive benefits, markers tend to either under- or over-score their peers. A dearth of literature that explores using peer assessment as a vehicle to decolonise the teacher education system exists. Informed by decolonisation, they generated data from one module presented at a rural university in South Africa. The module had 90 students enrolled. They gave students who were doing the module online openended questions for them to comment on. Of the 90 students, 59 students participated. Students had mixed feelings about peer assessment. Positive findings included peers being in accord of thinking as the assignments' authors, and enabling pre-service teachers for the school environment. Peers under- and over-scored one another because of carelessness, not reading with an understanding, and poor class attendance. The article concludes by challenging peer assessment implementers to put mechanisms in place to curb peers from either under- or over-scoring themselves.

The article by Milton Nkoane and Bekithemba Dube, 'Evoking Afrikan Grand-narratives as a Quest for Decoloniality to Champion Rural Knowledge Systems', proposes to disrupt the inequalities in the discourse that 
tends to subjugate 'other' forms of knowing and pushes these forms of knowing with vanity to the periphery in the corpus or pyramid of knowledge systems. In this regard, we zero in on rural epistemologies within the milieu of universities' knowledge creation. Knowledge systems have variances or a dichotomy informed by lived experiences which are not the same. Dominant discourses have been assertive in knowledge systems and domesticated other parameters for the interpretation of realities as historically out-of-date, irrational, and pre-modern. Through decoloniality theory and Grand Afrikan narratives, we challenge the hegemony in the knowledge industry where the tendency is to perpetuate injustices in knowledge systems especially when coming from the global south, more so in rural contexts. A consciousness of this intellectual piece aims to advance an argument that over and above the hegemonic discourses of the global north over 'other' forms of knowing, the boundaries could be ruptured in pursuance of equality and justice to 'other' forms of knowing. We answer two questions: what is it to decolonise the knowledge system in a higher institute; and how can rural knowledge gain access to mainstream knowledge production? This article probes difficult questions about hegemonic socio-political discourses in the knowledge industry. The line of argument is in pursuance of making an effort to refine, protect and defend 'other' knowledge systems and demystify knowledge as something that is presumed to be universal.

The purpose of 'Exploratory Study of TVET Stakeholders' Experiences of Implementing Work-Based Education in Rural Ecology', is to explore TVET stakeholders' experiences of implementing Work-Based Education (WBE) or Work-Integrated Learning (WIL) for students in rural ecology. The study by Phiwokuhle Ngubane, Dumsani Wilfred Mncube, Maria Siwela Mabusela, and Sunday Olawale Olaniran, was conducted at two campuses of the Umfolozi TVET College, in northern KwaZulu-Natal to understand their experiences. The National Certificate Vocational (NCV) is a new and modern qualification offered at FET Colleges since January 2007. It is offered at Levels 2, 3 and 4 of the National Qualifications Framework which are equivalent to Grades 10, 11 and 12. The NCV programmes were earmarked for the study in order to explore the suitability of these programmes for these learners in a rural context. Purposive sampling was employed to identify the sample size of six participants, which comprised campus managers, senior lecturers and WBE champions. The qualitative method was used to generate data. The findings reveal that college management does not prioritise the needs of TVET students 
or give necessary support to curriculum implementers on the ground to carry out the WBE programme to the benefit of learners from rural areas. It was also discovered that college management seems not to understand their role in ensuring compliance with regard to the implementation of WBE. It was evident that there is a need not only to maintain strong ties with existing hostemployers, but also to ensure that new host-employers are recruited to help address the shortage of places for students to do their workplace learning. The study recommends that there should be a clear vision for the implementation of WBE in the rural context, and that the vision should be clearly communicated to all role players to ensure effective implementation of the programme.

The purpose of the study, 'Grade Ten Teachers' Understanding of Multiple Intelligences in Teaching Physical Science in the Rural Context', by N. Pearl Blose and Blanche N. Hadebe-Ndlovu was to explore physical science teachers' understanding of multiple intelligences in teaching. Understanding multiple intelligences in teaching is very important in order to achieve effective teaching. The most important tenacity of this research is to show some of the observable structures of a holistic and constructive enriched curriculum for physical science that shapes the strengths of learners within the classroom. Human intelligence varies so much that each learner has a unique combination of intelligences resulting in a unique personal profile for each learner. As a result, each learner learns in a unique way. It is therefore, very important for teachers to understand multiple intelligences teaching, so that they may reach every learner when teaching. The traditional ways of teaching, catered for only mathematical and linguistic intelligences, leaving learners with other intelligences behind. When traditional ways of teaching are used, physical science is viewed as a difficult subject, because most learners fail the subject. This article presents an interpretive case study of four research participants who are grade ten, physical science teachers in a rural school in Durban, KwaZulu Natal. For data generation, narratives, one-on-one semistructured interviews and classroom observations were used. The study concluded that even though physical science teachers are showing the visibility of understanding multiple intelligence but they cannot articulate what multiple intelligences are. In their teaching there was visibility of the understanding of multiple intelligences, as they use multiple intelligences strategies unknowingly especially when they use visual aids.

Schools in multiple-deprived environments such as rural areas face a number of unmet needs. The unmet needs extend to science classroom 
practices in the form of pedagogies that continue to defy curriculum reform impetuses undergirded by important transformation agendas. Such is the case with the teaching and learning of physical sciences in schools located in multiple-deprived environments through inquiry-based practical work (IBPW). The instructional strategy is reform-oriented and also heavily sustained by both material and human specialist capital. Often one or both of these forms of capital are lacking in schools located in multiple-deprived environments. The lack of one of the capitals also restricts the function of the other. Using Sen's capability theory, this study teased out the shaping of a pedagogical framework to guide pre-service teachers as they facilitate IBPW in multiple-deprived physical sciences classrooms as part of a practical response to calls for the decolonisation of higher education. Against this brief background, this study is titled, 'Shaping a Pedagogical Framework to Guide Pre-service Teachers' Facilitation of Inquiry-based Practical Work in Multipledeprived Environments'. It is a qualitative case study of one South African Universities, by Maria Tsakeni. Data were collected by means of semistructured interviews with two science teacher educators. In addition, secondary data were also collected by means of document analysis of a secondary school chemistry syllabus to determine the pedagogical demands for IBPW. The findings indicated that methods courses for IBPW prepare preservice teachers for ideal science classrooms and not to function in multipledeprived conditions. The study identified three crucial capabilities for the preservice teachers to make IBPW accessible in multiple-deprived classrooms and opportunities for the decolonisation of the curriculum. A recommendation is made for methods curriculums to include courses to prepare pre-service teachers to function in multiple-deprived science classrooms.

The endeavour to impart sustainable knowledge in a postcolonial state is significantly hindered by legacies and cultures of subjectivity that are perpetuated long after declarations of independence. In the absence of the urban advantage, learners in educational institutions located in the margins tend to experience the heightened challenges of acquiring a sustainable education amid rurality. Learning English as a second language in former colonial spaces poses complex challenges for both the teacher and, especially, the learner due to the hegemony of English that thwarts epistemic access in various ways. This article by Sindiso Zhou, Nhlanhla Landa and Baba Tshotsho is titled, 'Indigenizing English in the ESL Classroom: Decolonizing Knowledge for Epistemic Access in Spaces of Rurality'. It interrogates the 
possibilities of decolonizing the educational experience in the language classroom to maximize epistemic access through indigenizing English using translanguaging. The study engaged in participatory observation of a purposively sampled first year class of university students doing an English for Specific Purposes course at the University of Fort Hare. While acknowledging the largely rural background of students in the sample, translanguaging was employed in the teaching of selected topics to measure content receptivity and student outcomes. The languages involved were English, isiXhosa and isiZulu. Through translanguaging, students participated with enthusiasm during discussions. In the absence of a negative affective filter and cognitive linguistic monitor that is characteristic of learning and speaking in English, students registered positive learning outcomes in both spoken and written assignments. During learning activities, facilitative crosslinguistic influence was acknowledged and explained. The findings established that students were conscious of the discriminatory and xenophobic nuances of scripted curricula as enacted by educators. Therefore, an attempt to redress this injustice through inclusion of, and appreciation for indigenous languages during learning through indigenizing English affirms students' identity, resulting in positive learning outcomes for marginalized and student populations in spaces of rurality.

Makeresemese Rosy Qhosola and Sechaba Mahlomaholo's 'Creating Decolonial Sustainable Learning Environments for the Fourth Industrial Revolution in the Rural and Urban Higher Education Contexts: A Study of Inclusive Management Strategies' explores some decolonial management strategies in four Higher Education Institutions in South Africa that seem suitable for the creation of Sustainable Learning Environments (SuLE), in anticipation of, and in the context of the Fourth Industrial Revolution (4IR). These strategies are considered to be decolonial in that they are inclusive and valorise other forms of managing beyond those that are conventional and western in orientation. Furthermore, they validate the local experience and the particularity of the individuals and institutions under scrutiny. There are currently demands for high levels of technological acumen within the higher education sector, hence the open labour markets. However, there are those workers and students in the Higher Education sector who are at the middle to lower end of the performance levels and who may be rendered superfluous and at risk of failure and dropping out, if they are unable to access these high-level skills and expertise. These tend to be left out as their institutions and societies advance technologically, resulting in increased 
inequality, unemployment rates, poverty levels and a subsequent deepening of the colonial arrangement of society. In order to address these challenges, there is a need for institutions to adopt management strategies that can create those sustainable learning environments in which all can succeed, regardless of their differences, thereby allowing for the transformation of society towards the desired decolonial state. This paper reports on how such management strategies are implemented in two urban, and two rural higher education contexts, respectively. In both categories of institutions; the physical, the physiological, the psychological and cultural modes of being human are used as bases for inclusive and decolonial management strategies which ensure success of all in the 4IR. These seem to give even more workers and students epistemic access to knowledge forms demanded in the 4IR era, irrespective of the geographical or socio-economic location of the institution, thereby ensuring cognitive justice for an even greater number of individuals. These strategies both advance and are anchored in complex problem solving, critical thinking, creativity, people management, coordination with others, emotional intelligence, judgement and decision making, service orientation, negotiation and cognitive flexibility - all of which constitute the context for a decolonial condition.

The life worlds, views, opinions and lived experiences of children with street life experiences are not sufficiently explored since these children are muted and relegated to the periphery of society. Researchers do not believe that these children can contribute suitable data and they are thus studied indirectly through adultist approaches in which adults serve as proxies. Researchers who adopt adultist approaches rely on adults' observations and views about the needs and lived experiences of at-risk youth. Therefore, the commonly held views on how streetism could be lessened are those of adults who have proximal interactions with children with street life experiences and not of street-involved children and youth themselves. In this article, 'Intercepting the Deluge of Streetism in a Rural Free State Town: The Views of Children-on-the-street', Macalane Malindi and Lineo Molahlehi report the findings of a qualitative study in which they explored how child migrations to the streets in a rural town in the Free State Province of South Africa could be prevented. They studied the children directly. The study involved 17 schoolgoing children who fell into the category of children-on-the-street since they kept ties with their families of origin. The participants were aged from 10 to 16 years and in grades ranging from 4 to 10 . The participants visited a drop-in centre run by a non-governmental organisation after school where they 
received meals before heading home. This qualitative study involved three focus group interviews with the participants sampled conveniently and purposively. Two focus groups consisted of six participants and one consisted of five participants. The data were subjected to inductive content analysis and the following broad themes emerged: stabilising family systems, providing opportunities for gainful employment, eliminating social exclusion and discrimination within families, and strengthening peer support. The findings were derived from the views of children-on-the-street themselves. The findings have implications for research and practice within the fields of social work, education and psychology.

The final article in this issue of Alternation, is titled, 'Rural History Teachers' Perspectives on the Significance of History' by Mbusiseni Celimpilo Dube. The rising trend internationally is for history to be taught in schools with a focus on historical significance so that learners may understand relationships between the past and contemporary issues. Given the importance of such an emphasis, the present study sought to explore the perspectives of rural history teachers about historical significance. In addition, the study examined the impact of rurality on the perspectives of these teachers. A qualitative approach was used to collect data by means of interperspectives in the King Cetshwayo education district, north of the Tugela River along the coast in KwaZulu-Natal. The participants consisted of seven professionally qualified history teachers who had taught history for at least five years in the Further Education and Training (FET) band. The findings revealed the perspectives of these teachers that studying history in a way that highlights historical significance develops learners' understanding of contemporary history and political knowledge, acquisition of life lessons, and local, national and global awareness of pertinent issues that affect everyday life. The findings also revealed that rurality impacted negatively on perspectivesof rural history teachers. This research study indicates the value of the potential of historical significance to equip and develop learners in the rural South African classroom with relevant historical knowledge and the ways in which rurality affects the way rural teachers look at issues affecting daily life.

\section{References}

Ndlovu-Gatsheni, S.J. 2013. Empire, Global Coloniality, and African Subjectivity. New York and Oxford: Berghahn Books. 
Sithole, T. 2014. Achille Mbembe: Subject, Subjection and Subjectivity. $\mathrm{PhD}$ Thesis Submitted at the University of South Africa. Pretoria.

Bekithemba Dube School of Education Studies University of the Free State DubeB@ufs.ac.za

Dipane Hlalele Educational Psychology School of Education Edgewood Campus University of Kwazulu-Natal hlaleled@ukzn.ac.za

Macalane Junel Malindi School of Psychosocial Education

North West University Macalane.Malindi@nwu.ac.za 